\title{
Lifelong learning and self: Work, subjectivity and learning
}

\author{
Stephen Billett, Griffith University, Australia
}

The relations among learning, work and subjectivity are discussed here to offer explanations about how individuals direct their learning throughout their working lives. These explanations are salient for informing policy and practice about learning for, through and throughout working life. The prospects for realising the kinds of goals that governments, employers and workers want to achieve through their ongoing learning are embedded in these relations, through identifying the kinds of conceptual premises needed to understand what motivates, directs and sustains that learning. Central here is the role that individuals' subjectivity plays in explaining the relations between individuals and their work and learning for work and the relationships among them. Four distinct conceptions of self are presented and discussed in terms of how that subjectivity is represented across and within perspectives informing considerations of work and learning. These different conceptions aim to open up and energise the emerging discussion about the role of self or subjectivity in relations among learning, subjectivity and work. Proposed here is the view that the self arises through social experience and stands as the personal basis that mediates relations about work and learning throughout working life.

\section{Learning through and for working life}

Maintaining and improving individuals' capacity to be effective in and across their work lives is held to be central to securing individual, local and national economic and societal well-being (OECD, 2000). At a national level, a common manifestation of this concern is a policy focus on developing and sustaining the competence of a skilled workforce able to maintain or improve national economic performance in an era of intense global competition. At the enterprise level, the concern is often about enhancing workplace efficacy and productivity to compete against imports or competitors and to provide goods or services that are exportable or more able to compete globally. Such is the importance of these imperatives that individuals are being mobilised by governments (Field, 2000) and employers alike to participate energetically and resourcefully in this global economic competition. Workers' ongoing competence is also seen as central to nations and enterprises being able to withstand or capitalise on other kinds of challenges such as those associated with transformations in technology and shifts in social or economic goals. Consequently, workers' ability to develop further and transform their occupational capacities throughout working lives is central to realising these goals. Yet, potentially confounding such goals is the growing emphasis in advanced industrial economies on individuals having to 'help themselves' in realising such goals (OECD 2000), with governments now increasingly concerned to 'enable' individuals, rather than provide for them (Edwards, 2002). This policy emphasis presents individuals' with potentially contradictory motivations for the focuses, direction and intensity of their lifelong learning: variously directed towards goals for the self or the imperatives of enterprise, community and nation. There is perhaps an assumption in all of this that goals aligned with personal interests, such as maintaining the continuity of individuals' employment and advancement will coincide with those associated with national economic health within nation states or the particular enterprise. Yet, this alignment has been shown to be difficult to achieve (Cho and Apple 1998). Instead, personal imperatives shape individuals' work and their relations with their workplace (Noon and Blyton 1997). 
This is not to suggest that the goals of individuals, enterprises and government are irreconcilable or inconsistent. However, it would be wrong to assume that individuals intentions for and processes of work life learning are going to be wholly consistent with those of them employers and government.

Therefore, we need to know more about what initiates and directs individuals' learning throughout their working lives. This includes how they exercise their agency in participating in and learning through work and on what bases and for what purpose is this agency exercised throughout their working lives.

Explanations of individuals' learning for and throughout working life have shifted away from a focus on workplace interventions, as in training, to a broader consideration of their learning. Central here is the role of individuals' engagement in and construction of knowledge. Increasingly, lifelong learning is seen as a both a component and outcome of individuals' engagement in work and work-related activities and interactions (e.g. Fenwick 2001, 2002, 2004; Hodkinson and Hodkinson 2003, 2004; Church and Luciana 2004). Such perspectives acknowledge that, beyond what is provided through intentional instructional interludes, or through workplace or governmental edicts, that personal factors shape workers' learning and development, (e.g. Billett and Somerville 2004, Fenwick 2002), and that workers' ongoing process of learning through everyday work activities are the key source of that development. Learning in this way is necessarily shaped by the diverse ways that individuals elect to engage in workplace activities. This process of engagement in work and workrelated learning is mediated by individuals' subjectivities (Allan 2005; Eteläpelto 2004; Billett \& Pavlova 2005; Fenwick 2004; Somerville and Abrahamsson 2003). That is, individuals' subjective dispositions shape and direct their thinking and acting, including how they construe and construct what the experience (i.e. what they learn). Here, the term 'self' is used alongside subjectivity, to make distinctions within these accounts and to offer sets of views about concepts of 'self'.

Yet, while there is a growing consensus about the role of subjectivity or self in that learning, there remains little agreement about the nature, sources and drivers of that subjectivity. Certainly, quite distinct conceptions of subjectivity are advanced across explanations of engagement in work-learning. Yet, most accounts concur that individuals' conscious awareness and unconscious desires, and personally-derived attachments shape their adoption of a particular subject position. Many accounts also emphasise the role of power in these positions, although debates continue about how to elaborate the interplay between power external to an individual (e.g. disciplinary norms and other social regulations) and power that appears to be of a personal kind (e.g., enacted as 'agency' or 'resistance' to subjection). Foucault (1979) notes the paradox of power that brings forth at the same time that it represses the subject, and simultaneously produces the conditions for subjects' resistance. Yet, here some authors view the self as being subjugated to the social world (Ratner 2000), and as merely a placeholder for social forms and practices (Newton 1998). Others, however, position subjectivity as the individual's project of constructing conceptions and dispositions to use in their engagement in the social world (Hodkinson \& Hodkinson 2004). For others still, there is a reflexivity associated with self that includes how individuals believe they are subject to the gaze of others (Fenwick 2004). In this way, subjectivity is aligned to personal and social identity, including the social and cultural forms and practices with which individuals elect to associate (Somerville 2006). Individuals' sense of self likely includes how they present themselves to and make sense of the social world (Goffman 1990), through their gaze or the discourses to which they have access (i.e. how they construe what they experience) (Kelly 1955). 
The contributions of different disciplines are quite helpful in articulating distinct perspectives of the same phenomena. Yet, these perspectives present both bases for and barriers to offering a single and unitary explanation of the sources, formation and development of individuals' subjectivity.

Indeed, disciplinary emphases (including my own) can also detract from considering other perspectives and premises. For instance, one reviewer of this paper did not like the reference to cognition within the account, claiming that it offers a too narrow perspective, and suggested that "subjectivity sits easier in more socially oriented frames". This comment reflected a concern about engaging with concepts form other disciplines, or those that might trouble personal preferences. Yet, to suggest that human cognition (i.e. thinking, acting, and, yes, learning) can be explained without a consideration of subjectivity or self is problematic, or that the term 'cognitive' needs to be expunged from such explanations is quite unhelpful and limiting in itself. Another reviewer rehearsed the claim that Piagetian and sociocultural perspectives were quite distinct even though close examination on what Vygotsky is thought to have proposed and what Piaget wrote about has far more similarities than differences. Indeed, a key Vygotskian scholar (Valsiner) has suggested that Vygotsky was indeed a good Piagetian. Again, taking this personal emphasis further, another reviewer suggested that the Piagetian position was akin to Darwinism and emphasised natural selection to adaption with the brute world. This (unsubstantiated) claim ignored or is oblivious to Piaget's (1968) concept of equilibrium taking into account both the balancing of the social and the brute world. Such misunderstandings can easily arise in accounts that seek to make distinctions amongst theoretical emphases. So, beyond a common focus of interest, distinct disciplines and the perspectives of those who engage in, the lack of ease in accommodating the language and conceptions of other disciplines and, also a lack of reflexivity in and about such a project, all make securing an consensual and unitary conception of self or subjectivity quite difficult. So, while different disciplines provide salient worldviews and explanations of lifelong learning, they are not easily reconciled.

So, even if it were possible, there is no attempt here to be wholly comprehensive of the various accounts of concepts such as subjectivity and self nor to engage with the particular nuances of each discipline. The attempt here is to explain these conceptions and how they might shape particular understandings of learning throughout working lives. In the conception adopted here, subjectivity is sociopersonal. That is the personal premised construction and projection of their conceptions, procedures and sense of self as directed by individuals' agency and intentionally. Yet, this subjectivity arises through socially-derived but personally unique processes of on-going learning (micro-genetic development) (Scribner 1985) that shapes how individuals engaged in work and in turn reshape and remake that work through their enactment of it. So, through its exercise, individuals' sense of self or subjectivity is positioned and prone to being transformed

Aligned with the exercise of their subjectivity in seeking to secure, maintain or transform the self (i.e. maintain ontological security) are individuals' personal epistemologies (Smith 2005) through which their agency and intentionality are exercised in directing the purpose, intensity and direction of their work and learning throughout working life. These epistemologies are often subsumed within accounts of individual agency and intentionality that explain the purposes, intensity and direction of individuals' work and learning throughout working life. It follows that, together, considerations of subjectivity, self and personal epistemologies stand to inform the 
motivations for and processes of individuals' engagement in learning through work life and throughout working life.

In discussing and elaborating these premises, this paper commences by defining the terms lifelong learning, work and subjectivity. In doing so, it also explicitly addresses the different contributions and conceptions of subjectivity and how these both support and make difficult the task of securing a broadly acceptable account. Given the relations among these conceptions are located in discussions about the degree of their embeddedness in the social suggestion or individual agency, the following section seeks to elaborate how these ideas are discussed across key theoretical disciplines. This then leads to illuminating these different conceptions by proposing four accounts of self located in the literature aligned to subjects and subjectivity. In all, these accounts of self, rehearse and remind in different ways and degrees that the enactment of work, the learning for it and the kinds of remaking of practices required to respond to changes, and that lifelong policies and practices need to include a consideration of those who work and learn.

\section{Defining lifelong learning, work and subjectivity}

In order to consider the relationship among learning, work and subjectivity and how together they can inform distinctive use about self as it is applied to lifelong learning, it is necessary to attempt some definitions of these terms to offer some premises from which the discussion in this paper proceeds.

\section{Lifelong learning}

The term 'lifelong learning' has become association with learning for and throughout working life since the Year of Lifelong (OECD 1996) when the term was appropriated for these very purposes. Prior to that time, lifelong learning was more commonly associated with learning to enrich and broaden adults' lives through cultural or recreational pursuits. Here, however, a human development perspective is favoured. Lifelong learning is seen as an inevitable and ongoing process of development (i.e. ontogenetic development) that occurs through individuals' engagement in conscious and non-conscious thinking and acting throughout their lives (Billett 2006b, Lave 1993, Rogoff 1990). Change or learning occur constantly through individuals deploying their cognitive resources (i.e. what they know and how they know) when engaging in activities and interactions with the world beyond them, and from which arises the conceptions, dispositions or procedural capacities needed for work. This ongoing and moment-by-moment process of learning (i.e. micro-geneses) contributes to individuals' development across the lifespan or ontogenetic development (Rogoff 1990, Scribner 1985). Hence, when engaging in goal-directed work activities and interactions, learning arises. When those activities are familiar, much of the learning likely comprises the reinforcement, refinement or extension of what individuals' already know. However, when confronting experiences, individuals construct new knowledge.

Importantly, the learning arising from every day and ongoing experiences is more than the development of narrowly defined cognitive capacities (i.e. occupationally specific concepts and procedures). In addition, this development includes and how individuals' interpret the world, understand and use the discourses available to them. Instead, individuals' cognitive experience (Valsiner 2000) (i.e. their conceptions, understanding, procedures, interest), these have arisen pre-mediately: from earlier personally-shaped experiences. Consequently, how individuals engage with and subsequently learn from what they experience is likely to be person- 
dependent in some ways (Billett 2003), because their experiences are in some ways personally unique. What is learnt and how that learning occurs is shaped by individuals' construal of their experience. That is, whether it is familiar or novel to them, more or less interesting. So, individuals' engagement in work activities and the deployment of their cognitive resources is directed by their subjectivities. Hence, the process of lifelong learning is characterises by the negotiation between individuals' conceptions and what they experience in their interactions with physical and social environment. These conceptions are elaborated and, in particular, this learning arises through a relational interdependency amongst social, personal and brute factors (Billett 2009). Yet, within these relations, individuals' sense of self and the agency with which that agency is enacted, stands as mediating these relationships and what and how they learn. This key mediating role is how individuals make sense of what they experience underscores the salience of placing the subject in discussions about work and learning through and for work.

\section{$\underline{\text { Work }}$}

Paid work comprises individuals' engagement in goal-directed activities (i.e. occupations) that usually arise from social and cultural needs. However, these activities are often shaped by the circumstances of their manifestation these practices can have particular meanings for the individuals who engage with them (Billett 2003). Therefore, although paid employment usually has cultural origins and is manifested in particular ways in specific workplace settings, it also has personal dimensions. For instance, Martin (2001) suggests that "vocations are the work we choose to do as distinct from the job we have to do" (257). That is, while work can be seen as activities and interaction that are observable by others, its enactment is fundamentally realised through the deployment of human subjectivities. These subjectivities shape how the work is conceptualised, engaged with and conducted (Billett 2006a). Therefore, work activities are subject to personal process of construing and deploying working knowledge.

Consistent with this, work undertaken at home, in the community, workplaces and educational institution are not conceptually discreet. So, the discussion above also accounts for non-paid work. Yet, this focus on the personal needs to account for the complex of factors that shape individuals' working lives including social interactions, workplace communities, particular discourses and factors associated with societal standing of that work and individuals' occupational identity (Noon \& Blyton 1997). These factors include the particular social and culturally-derived expectations of those work activities, their status, how individuals participate in work and what performances are required in particular workplaces. Yet, as noted, more than a societal expectation expressed as a cultural requirement or norm (i.e. doctors' competence includes being discreet about patients' health and treatment), localised manifestation (i.e. what it requires to be a competent doctor in a particular location) there is the subjectively premised bases of what constitutes paid work to the individual as shaped and mediated by their sense of self, as a doctor, at the instance. For instance, paid work is widely held as being central to adults' personal identity and well-being (e.g. Noon \& Blyton 1997; Pusey 2003), and, therefore, their sense of self is constantly exercised to be seen as being effective in that occupation (Billett \& Pavlova 2005, Billett, Smith \& Barker 2005). However, for some, paid work is a merely a means to an end. A well-paid and secure job can also provide a platform for individuals to engage in activities outside of working life to which they are committed (e.g. church, family, community). In this way and for these individuals, paid work 
might well be an unwelcome, but necessary intrusion into their lives, yet it does not comprise their vocation. Hull (1997), for instance, refers to Hispanic women in America who have to find relatives to care for their own children while they engage in paid employment looking after the children of wealthy American professionals. Even including fulfilling the needs to earn a wage, subjective experience most likely directs individuals' participation in and their enactment of work. Indeed, the difference between what constitutes just paid employment and individuals' vocations is the degree by which they identify with and assent to their work as being vocation (Dawson 2005). Consequently, although work is founded in culturally-derived practices that that have social and cultural purposes, it is enacted in ways shaped by individuals' subjectivities.

\section{Subjectivity}

As noted, the term 'subjectivity' is used in different ways, across disciplinary divides. Others use related conceptions, such as 'identity'. Hence, it is important to define and differentiate subjectivity from other associated and perhaps analogous concepts. Here, subjectivity is seen to comprise the conscious and non-conscious conceptions, dispositions and procedures that constitute individuals' cognitive experience (Valsiner and Van de veer 2000): our ways of engaging with and making sense of what we experience through our lived experience. The salience of subjectivity is its central role in the personal process of construing, constructing and responding to what individuals encounter in the world beyond them. Activities such as sense making are "perhaps the most crucial site of political struggle over meaning, given it involves personal, psychic and emotional investment on the part of the individual" (Weedon 1997:76). Although some from other disciplines remain discomfited by a term such as cognitive, perhaps because of particular associations with narrow conceptions, the term cognitive experience is used here to elaborate the conceptual, procedural and dispositional premises that direct individuals' intentionality, focus and intensity when engaging with the physical and social environment beyond them. Through subjectively experiencing, which variously shapes and, at times, directs our conscious thinking and acting our cognitive experiences is reinforced, refined and transformed. Hence, individuals' subjectivities comprise a set of conceptions, procedures beliefs and values and dispositions that are, in part, non-conscious (yet quickly become conscious when something we experience does not fit) and, in part, conscious. Therefore, individual subjectivities are essential to understanding engagement in work and learning, and how, for instance, workers respond to requests from employers and governments to direct their learning in particular ways.

Together, these bases of subjective experience are central to individuals' learning and working. They find expression in two forms. There is the individual's sense of self that guides the degree and intentions of our conscious thinking and acting strategically in seeking ontological security (Newton 1998). Similar to Piaget's concept of equilibrium, the sense of self is exercised to secure personal coherence in encounters with the social and brute world and to overcome or reconcile disequilibrium, and does so from a platform of personal cognitive experience. Indeed, Giddens (1991) suggests the problem for the self is in maintaining its security in circumstances that threatens its stability and the reference points for that stability. This imperative seems to explain individuals negotiating their self as workers in contemporary turbulent workplaces. Knight and Willmott (1994) referred to the fragility of the self in attempting to cope with post-modernity. Certainly, studies of workers' participation in working life over time and through processes of change 
(Billett et al 2004, Billett and Pavlova 2005, Billett, Smith and Barker 2005) suggest that while constrained and shaped by situational factors, social practices and cultural mores, as in bounded agency (Evans 2004) individuals are still able to exercise their agency in ways aligned with maintaining and developing a further their sense of self as a worker. These studies found that ontological security was negotiated between both the personal and social.

The concept of 'identity' is also associated with subjectivities and also has both personal and societal connotations. Socially, institutional, normative and discourse practices that are often associated with individual's identity. Occupations, for instance, provide examples of these, and are ordered and valued in particular ways. So, there are societal expectations and esteem associated with occupation such as a car mechanic, medical doctor, nurse, hairdresser etc, as these can be aligned with broader social categories (e.g. masculinity). Identity is also aligned with how individuals identify with and wish to be associated the social world. In this way, identity is seen as an outcome, a narrative construction that is a product of this process and, in ways, analogous to Heidegger's concept of Daesin - of being through reflection (e.g. Ezzy 1997). Hence, the agentic qualities of subjectivities or sense of self as defined above makes it quite distinct from many of the accounts of identity, which refer more to individuals sense of themselves rather than an account which includes the active and transformative qualities of subjectivity.

It follows from the above that to explain what motivates and directs individuals' learning through work and throughout working life requires accounting for the relations among work, subjectivity and lifelong learning or ontogeny. Standing at the centre of relations are individuals' subjectivities or self. Yet, while being central to these relational, there are distinct accounts and conceptions of subjectivity and self, which although not reconcilable required to be arrayed so that the explanations they offer to lifelong learning can be more fully apprehended.

\section{Accounts of subjectivity}

Although central to understanding learning throughout working life, the conception of subjectivity has particular and distinct meanings across the disciplinary divide.

Consequently, some delineation of these conceptions is helpful, not in order to secure a uniform account, but to elaborate how they help inform the process of lifelong learning. A starting point is the commonly held view that subjectivities are something constructed by the subject (Mansfield 2000). A key point of distinction is, however, the degree by which the personal or social, or some combination of both, play in that construction. Arising from the 'enlightenment' was the idea of the free and unconstrained nature of the self. Rousseau (1968) emphasised the uniqueness, autonomy and absolute governing freedom of individual experience. In describing this tradition, Orner (1992) suggests that 'subject' refers to something quite different than the common usage of the term 'individual'. Citing Sarup (1989), she suggests that the individual is often conceptualised as a free, intellectual agent whose thinking processes are not constrained by historical or cultural circumstances. Similarly, Kant (cited in Mansfield 2000) claims that every experience individuals have, from those simple sensory perception to complex ideas, can only be understood in terms of how the individual experiences it. Goffman (1990) is a more contemporary proponent of such a view. It seems these kinds of traditions informed the development of adult humanistic learning theories premised on self-actualisation (e.g. those of Rogers and Knowles). Yet, these perspectives may well overplay the role of human 
consciousness, by positioning the individual as being personally unique and disassociated with and from social and physical environments with which they engage.

A more contemporary orthodoxy is that the reproduction of subjectivities and culture (Luke 1992) are socially structured and individuals are subject to and subjugated by social structures (e.g. norms, practices, discourse etc). Foucault's (1979) earlier position, render individuals as mere placeholders in social networks (Mansfield, 2000) because they are enmeshed in social structures and in ways that is held to diminish and deemphasise personal autonomy (Ratner 2000). Individuals here are positioned to be produced by the social world, rather than being in a relationship with it. That is, the social is the condition of the emergence of the individual. Similarly, Bourdieu (1991) refers to battery of societal dispositions, comprising a habitus that orientate individuals' actions and leave an intra-psychological legacy (i.e. a learnt change in individuals). He cites, for example, how communicating with others through language results in a legacy comprising individuals' dialects. These are not born within us, but learnt through interaction with social partners that deploy these accents, yet become almost indelible learnt, and are hard to dispense with. Yet, against such a socially deterministic position, Mansfield (2000) claims subjectivity defies our separation into distinct selves and helps us to understand why, our interior lives inevitably are seen to involve other people, either as objects of need, desire and interest what was necessary sharers of common experience.

This kind of account also responds to the criticism that the subject is missing in discussions about work and learning (e.g. O'Doherty and Willmot 2001, Luke and Gore 1992). Yet even they fail to adequately grant an adequacy to the role of the subject in negotiating meaning (e.g. sense of self and identity). Equally, criticism can be advanced against other explanations of thinking and acting (i.e. learning) that emphasise the social contributions to human cognition, and deny the role of the subject. Certainly, the subject is denied, minimised or otherwise underplayed, in the accounts provided about communities of practice (Wenger 1998), activity systems (Engestrom 1993) that are commonly used explain learning in and through work, for instance. Because they deny the role of personal agency, these kinds of accounts also fail to fully accommodate how power relations between the personal and social are experienced and enacted (Newton 1998) including the role of the subject as being both an exerciser of power and being subject to it (Fenwick 2006).

Following this, Foucault's consideration of desire (1987) has been used to elaborate either his emphasis on power relations (O'Doherty and Willmot 2001) or to some his almost Rousseau-like conception of human freedom through separating pleasure from the relations of power (Burkitt 1993, cited in Newton 1998). Regardless, it elevates the role of the subject's desire as being disassociated with social forms. Certainly, Weedon (1997) in her definition of subjectivity grants space for "both the conscious and unconscious thoughts and emotions of the individual, presentation of herself and her ways of understanding her relations to the world (p.32)". She continues, that "whereas humanistic discourses propose that at the heart of all individuals is an essence which is unique, fixed and coherent and makes her what she is, the post-structuralist approach proposes subjectivity as being precarious, contradictory, and in the process, constantly being reconstituted in discourses each time we think or speak" (p.32). So, here, individuals' uniqueness of arise from negotiated relations between the personal and the social across personally-particular experiences, whereas the humanist tradition is more about the individual arising uniquely and through personal negotiation and preference, and that development leads to attributes which remain fixed. 
Providing licence for both the humanistic and post-structural viewpoints, Taylor (1985) proposes that while humans are not alone in having desires and motives in making decisions and some capacity to choose between desires, a particular characteristic of humans is the ability to form second order desires. That is, the capacity to evaluate our desires, and be self reflective in that evaluation. Further, the sociologists of knowledge Berger and Luckman (1967) provide a space for both of these possibilities, stating that socialisation is never completely successful. They claim that some individuals are able engage with the 'transmitted universe' ( $\mathrm{p}$ 124) more so than others, and that individuals are more or less able to engage with that universe. Also, Mansfield (2000) suggests that subjectivity is "primary on experience, and remains firmly into inconsistency, contradiction and unselfconsciousness. Our experience of ourselves remains forever prone to surprising disjunction and that only the fierce lives of ideology or theoretical dogma convince us we can be homogenised into a single consistent thing." (p. 6)

Consequently, the idea that individuals' immediate and ongoing experience of social world as un-problematically leading to socialisation - the simple transmission of the social to the individual -is highly questionable. Foucault claims that he never intended "to ruin the sovereignty of the subject" (Mclaren 1997: 112). Indeed, the realist philosopher Bhaskar (1998), claims that sociological explanations are not about mass action, but relations between individuals and social practices. Similarly, through his concept of structuration, Giddens (1984) proposes a key role for personal agency in the social structuring of knowledge. Individuals' engagement and their agency seems necessary not only for their own continuity, but also that of social systems. Pointedly, Giddens (1984) proposes that "social systems do not reproduce themselves but require the active production and reproduction of human subjects" (p.11). Yet, other sociological accounts offer more nuanced explanations about the relations between personal and social factors. Rose (1990) refers to the 'enterprising self' when individuals self-regulate and self-subjugate themselves to social world. Grey (1994), for instance, refers to how accountants mask and manipulate their 'sense of self' and present a particular kind of self in order to secure employment and promotion within an accountancy practice. Elsewhere, individuals are found not to be so constrained as to lose their sense of self and personal identity. Instead, workers report being able to negotiate workplace activities while maintaining and transforming their sense of self: being themselves (Billett and Pavlova 2005, Billett, Smith and Barker 2005). Yet, O'Dohery and Willmott (2001) hold that even these kinds of negotiations are shaped in ways that deny fulsome personal agency.

A consideration of these accounts suggest the need to neither privilege the social or the personal, but the relations between them, and how through these negotiations the bases of self might be best explained. This extends to individuals negotiating away part of that sense of self it to achieve particular personal goals (e.g. Grey 1994). Yet, such a concession also acknowledges the central role of individuals' intents and agency. Indeed, one way to read among these accounts is through their positioning of the relations between the individual and the social as arising through ontogenetic development (Scribner 1985) that comprise processes of ongoing negotiations between the social and the personal. Yet, because the personal and the social emerge in the processes of work and learning, the personal is seen as a key premise to understand what constitutes the subject and her or his unique sociopersonal subjective qualities. The individual is a person and body that has engaged with and endured both the brute and social world. In this way, the individual as a personal entity represents an epitome of the social because she/he evolves from a 
complex of social forms and practices that is both shaped by and shapes these social forms through its engagement with them throughout their life.

Together, and from the above, there are traditions that privilege conceptions which are helpful in appraising the completeness, orientation and coherence of one's own conceptions. Given that in a number of accounts the self is seen as reflecting the agentic qualities of subjectivity -- the degree by which it is able to act - this becomes a helpful concept to capture how it is conceptualised across these disciplines.

\section{Four accounts of self}

From the discussions above and other perspectives, four distinct accounts of self as subjectivities can be delineated from the literature referred to above. Self here is used as a proxy for subjectivities, but to provide some distance to permit their presentation lightly unshackled from the contested term of subjectivity. These four accounts are delineated to elaborate these distinct conceptions and identify how they inform the project of lifelong learning. They comprise the: (i) Autonomous Self; (ii) Subjugated Self; (iii) Enterprising Self; and (iv) Agentic Self (see Table 1). However, these accounts of self are not comprehensive, wholly inclusive and will be subject to criticism by some, and perhaps many, as evidenced in the detailed and divergent reviews that this manuscript generated. Nevertheless, while acknowledging there are distinct accounts of subjectivity and self that are not easily reconciled, by offering and making distinct these accounts, the explanations they provide about lifelong learning collectively and individually can be more fully apprehended. Others may have undertaken this task differently and offered other delineations of these accounts. The delineation offered here is not intended as a final position and its very representation will likely and hopefully precipitate invigorate further debates about the position of the subject in learning through and for work.

It is on these premises that each of these conceptions is now briefly described to articulate their particular orientations to work and learning. They are presented in a continuum in order of presentation and from left to right in Table 1 that roughly reflects their development over time. The Autonomous Self is where individuals are viewed as being able to exercise of autonomy and freedom in realising their desired goals. The tradition here is humanism. The key ideas here are from Rousseau (1968) the absolute freedom of individual experience and their uniqueness, Descartes (Cottingham 1996) motif of "I think therefore I am" and Heidegger's (1975) concept of authentic individualism. Learning here is the free and spontaneous expression of self (Mansfield 2000) and the securing of self actualisation (e.g. Rogers 1969).

Table 1 - Four accounts of self: Autonomous, Subjugated, Enterprising and Agentic

\begin{tabular}{|c|c|c|c|c|}
\hline & Autonomous self & Subjugated self & Enterprising self & Agentic self \\
\hline Definition & $\begin{array}{l}\text { Individual exercising } \\
\text { autonomy and freedom } \\
\text { in realising their } \\
\text { desired goals - 'being } \\
\text { one's self'. }\end{array}$ & $\begin{array}{l}\text { Individual as a mere } \\
\text { placeholder within } \\
\text { social systems }\end{array}$ & $\begin{array}{l}\text { Self reflexive, } \\
\text { entrepreneurial } \\
\text { individual formulating } \\
\text { and maintaining } \\
\text { identity agentically } \\
\text { within yet also } \\
\text { transforming social } \\
\text { system }\end{array}$ & $\begin{array}{l}\text { Individual selectively } \\
\text { engaging and } \\
\text { negotiating with social } \\
\text { suggestions to secure, } \\
\text { developed, maintain } \\
\text { their identity }\end{array}$ \\
\hline $\begin{array}{l}\text { Relation } \\
\text { to social } \\
\text { structures }\end{array}$ & $\begin{array}{l}\text { Autonomous from } \\
\text { social structures - } \\
\text { 'separated' }\end{array}$ & $\begin{array}{l}\text { Embedded in social } \\
\text { structures - } \\
\text { 'enmeshed' }\end{array}$ & $\begin{array}{l}\text { Continuity found } \\
\text { within social structures } \\
\text {-'entangled' }\end{array}$ & $\begin{array}{l}\text { Negotiating selectively } \\
\text { and relationally with } \\
\text { social structures - } \\
\text { 'entwined' }\end{array}$ \\
\hline Tradition & Humanist & $\begin{array}{l}\text { Structuralism (early } \\
\text { Foucault) }\end{array}$ & (Late) Modernity & Post-structural \\
\hline
\end{tabular}




\begin{tabular}{lllll} 
Learning & $\begin{array}{l}\text { Casting off social } \\
\text { subjugation, being } \\
\text { able to be oneself } \\
\text { without constrained by } \\
\text { or historical legacy to } \\
\text { content with }\end{array}$ & $\begin{array}{l}\text { Social subjugation and } \\
\text { shaping through } \\
\text { engagement with the } \\
\text { social world. }\end{array}$ & $\begin{array}{l}\text { Self-regulated efforts, } \\
\text { subjugated to work } \\
\text { force practices and } \\
\text { outcomes, seeking a fit } \\
\text { between personal } \\
\text { goals and enterprise }\end{array}$ & $\begin{array}{l}\text { Resisting, out- } \\
\text { manoeuvring, avoiding } \\
\text { strong social } \\
\text { suggestion through } \\
\text { locating a position and } \\
\text { role within social } \\
\text { practice which is } \\
\text { consistent with } \\
\text { individual subjectivity } \\
\text { and identity. }\end{array}$ \\
$\begin{array}{l}\text { Concept of } \\
\text { subjectivit }\end{array}$ & $\begin{array}{l}\text { Free and spontaneous } \\
\text { expression of self }\end{array}$ & Placed under social \\
structures & Presentation of self & $\begin{array}{l}\text { Open, reflexive, } \\
\text { embodied quality of } \\
\text { human agency }\end{array}$ \\
\hline
\end{tabular}

The Subjugated Self is where the self is positioned as being subjected to social structures and social press. In short, the individual is embedded or enmeshed within social structures, with agency being granted to these social structures, and their press or suggestion, not the individual. The tradition here is in the early work of Foucault and the view of Marx about individuals developing a false consciousness would be consistent with this view. Learning within this conception of self is about socialisation and subjugation - being shaped by social world, with analogies to behaviourism. The concept of subjectivity here is about being 'placed under' or posterior to social structures is also exercised with the tradition of labour studies.

Indeed, the Enterprising Self is where individuals both self-regulate and selfsubjugate themselves, while performing particular roles within and through their working life. The individual here is entangled within social structures and forms, yet playing a active role in that entanglement, and their disentanglement. The tradition here is late modernity. The ideas of Rose (1990) about the entrepreneurial self, and Du Gay's (1996) view of individuals as being autonomous, self regulated and productive. The conception of subjectivity here is about the presentation of self. Learning here might refer to resolving regulated efforts which seek a fit between social norms and practices and individuals goals, as in securing ontological security.

The Agentic Self is where the self is able to both selectively engage and negotiate with the social suggestion that is directed by the intention to secure, develop and maintain their identity and ontological trajectory. Key ideas here emanate from O'Doherty and Willmott (2001) about the reflexive and embodied quality of human agency and also Weedon (1997) who refers to the reflexivity of self. The concept of subjectivity here is about conscious and unconscious thoughts and emotions and ways of understanding relations with world. Learning here is about resisting, out manoeuvring and negotiating with strong social suggestions and locating a role, and sense of self that is consistent with individuals' emerging subjectivities.

These accounts of self, while reflecting sets of evolving ideas, have within them particular emphases and values that suggest different kinds of relations between the social and the individual. The privileging of particular kinds of emphases (either the social or the individual) is evident across theoretical perspectives within the major disciplines (i.e. philosophy, psychology and sociology) and beyond. What they suggest is that lifelong learning as presented in these different accounts of self have distinct purposes and processes. They differ from being directed towards excising the individual (i.e. lifelong learner) from the subjugation of the social through to negotiating identity, reconciling and accommodating the personal and the social, to actively resiting and reconstructing both self and society.

\section{Self and lifelong learning}


There is much commonality of purpose in considerations of individuals' learning throughout their working lives. Governments and enterprises want workers to remain highly skilled across their working lives. But there are also differences in the ways that the interests of governments, employers and workers might conceive of the purposes and processes of lifelong learning. Moreover, the conduct of work is important to individuals' sense of self and being. Work and being seen to undertake that work effectively are central to most individuals that work (Noon and Blyton 1997). Furthermore, learning arises in particular ways through individuals' participation in work, not as separate or discreet processes. In this way, how individuals engage in work and work related activities has repercussions for and beyond individuals themselves. At the heart of effective work and learning practices is the conduct of work that is salient and meaningful for individuals' sense of self and identity and its effective conduct is increasingly essential to maintaining and developing workplaces' capacities in the turbulent and globalised contemporary work context. Aligned here are also important national goals about maintaining or improving the national standard of life, and beyond the profitability of public and private enterprises is the quality of the goods and services that workers want to provide.

Central to all of these concerns is the importance of understanding individuals as subjects engaged in work, learning through that work and, in doing so, also, remaking work practice. In governments seeking to mobilise workers, on the one hand, and propose that individuals take charge of their own development, on the other, a great emphasis is being placed upon individual agency and intentionality in maintaining their effectiveness through working life. In effect, the mobilisation of self seems to be the core and perhaps most salient premise being advanced here. Yet, this empowerment will not just be directed to reflecting government and employers' goals, if at all. It is most likely be enacted in individuals' interests: their goals, interests and sense of self. It is these that will negotiate learning, realise the enactment of power and achieve the level of consonance among government, employer and individual intents. What is also required is for the relations between the individual and those environments to be appreciated, understood and embedded within accounts of learning through work and working life. Hopefully, through providing accounts, bases and premises for the further elaboration of learning through and for work to be more wholly elaborated. In all, these accounts of self, rehearse and remind in different ways and degrees that the enactment of work, the learning for it and the kinds of remaking of practices required to respond to changes, and that lifelong policies and practices need to include a consideration of those who work and learn.

Acknowledgements. Thanks to Margaret Somerville and Tara Fenwick for the earlier productive interactions and discussions that informed this paper. This manuscript is a revised discussion within the opening chapter of an edited monograph (Work, Subjectivity and Learning). Also, a contributor to a journal is rarely treated to three such comprehensive and thoughtful (and contradictory) reviews with which to engage with and negotiate across when revising a submission. So, thanks to these anonymous reviewers. The only matter of which I am confident, is that none will be satisfied with the final version.

\section{References}

Allan, J.K. (2005). Farmers as learners: Evolving identity, disposition and mastery through diverse practices. Rural Society: The journal of research into rural and regional social issues for Australia and New Zealand, (pp.4-21).NSW Australia: CRSR.,Charles Sturt University. 
Berger, P. L., \& Luckman, T. (1967). The Social Construction of Reality. Harmondsworth, Middlesex: Penguin Books.

Bhaskar, R. (1998). The possibility of naturalism. London: Routledge.

Billett, S (2009) Conceptualizing learning experiences: Contributions and mediations of the social, personal and brute, Mind, Culture and Activity 16 (1) 32-47

Billett S (2006a) Work, change and workers. Springer, Dordrecht, The Netherlands

Billett, S. (2006b). Relational interdependence between social and individual agency in work and working life. Mind, Culture and Activity, 13(1).

Billett, S. (2003). Sociogeneses, Activity and Ontogeny. Culture and Psychology, 9(2), 133169.

Billett, S., Smith, R., \& Barker, M. (2005). Understanding work, learning and the remaking of cultural practices. Studies in Continuing Education, 27(3), 219-237.

Billett, S., \& Pavolva, M. (2005). Learning through working life: self and individuals' agentic action. International Journal of Lifelong Education., 24(3), 195-211.

Billett, S., \& Somerville, M. (2004). Transformations at work: Identity and learning. Studies in Continuing Education, 26(2), 309-326.

Bourdieu, P. (1991). Language and Symbolic Power (Edited by J.B. Thompson). Cambridge: Polity Press.

Cho, M. K., \& Apple, M. (1998). Schooling, work and subjectivity. British Journal of Sociology of Education, 19(3), pp269-291.

Church, K.and Luciana, T (2004). Dancing Lessons: A Choreography of Disability in Corporate Culture. Paper presented at the WALL Annual Meeting, Toronto.

Cottingham, J. (Ed.). (1996). Western Philosophy: An anthology. Oxford: Blackwell.

Dawson, J. (2005). A history of vocation: tracing a keyword of work, meaning, and moral purpose. Adult Education Quarterly, 55(3), 220-231

Du Gay, P. (1996). Consumption and Identity at Work. London: Sage.

Edwards, R. (2002). Mobilizing lifelong learning: governmentality in educational practices. Journal of Educational Policy, 17(3), 353-365.

Engestrom, Y. (1993). Development studies of work as a testbench of activity theory: The case of primary care medical practice. In S. Chaiklin \& J. Lave (Eds.), Understanding Practice: perspectives on activity and context (pp. 64-103). Cambridge, U.K: Cambridge University Press.

Eteläpelto, A (2004) Developing subjective identities of teachership through participation. EARLI conference on Professional Development, Regensburg, Germany (October 2004)

Evans, K. (2007). Concepts of bounded agency in education, work, and the personal lives of young adults. International Journal of Psychology, 42(2), 85-93.

Ezzy, D. (1997). Subjectivity and the Labour Process: Conceptualising'Good Work'. Sociology, 31(3), 427-444.

Fenwick, T. (2004). Learning in portfoliowork: anchored innovation in and mobile identity. Studies in Continuing Education, 26(2), 229-246.

Fenwick, T. (2002). Lady, Inc.: women learning, negotiating subjectivity in entrepreneurial discourses. International Journal of Lifelong Education, 21(2), 162-177.

Fenwick, T. (2001). Tides of Change: New Themes and Questions in Workplace Learning. In T. Fenwick (Ed.), Sociocultural Perspectives on Learning through Work (pp. 3-18). San Francisco: Jossey Bass.

Fenwick, T. (1998). Women's Development of Self in the Workplace. International Journal of Lifelong Learning, 17(3), 199-217.

Field, J. (2000). Governing the ungovernable: why lifelong learning promises so much yet delivers so little. Educational Management and Administration, 28(3), 249-261.

Foucault, M. (1979). Discipline and punishment. New York: Vintage Books.

Giddens, A. (1991). Modernity and self-identity: Self and Society in the Late Modern Age. Stanford: Stanford University Press.

Giddens, A. (1984). The constitution of society. Cambridge: Polity Press. 
Goffman, E. (1990). The presentation of self in everyday life. London: Penguin Books.

Grey, C. (1994). Career as a project of the self and labour process discipline. Sociology, $28(2), 479-497$.

Heidegger, M. (1975). The Basic Problems of Phenomenology (A. Hofstadter, Trans.). Bloomington: Indiana University Press.

Hodkinson, P. H., \& Hodkinson, H. (2004). The significance of individuals' dispositions in the workplace learning: a Case study of two teachers. Journal of Education and Work, 17(2), 167-182.

Hodkinson, P., \& Hodkinson, H. (2003). Individuals, Communities of Practice and the Policy Context. Studies in Continuing Education, 25(1), 3-21.

Hull, G. (1997). Preface and Introduction. In G. Hull (Ed.), Changing work, Changing workers: Critical perspectives on language, literacy and skills. (pp. 3-39). New York: State University of New York Press.

Lave, J. (1993). The practice of learning. In S. Chaiklin \& J. Lave (Eds.), Understanding practice: Perspectives on activity and context (pp. 3-32). Cambridge, UK: Cambridge University Press.

Leontyev, A. N. (1981). Problems of the development of the mind. Moscow: Progress Publishers.

Luke, C. (1992). Feminist politics in radical pedagogy. In C. Luke \& J. Gore (Eds.), Feminisms and Critical Pedagogy (pp. 25-53). New York: Rutledge.

Kelly, G. A. (1955). The psychology of personal constructs New York: Norton.

Knights, D., \& Willmott, H. (1989). Power and Subjectivity at Work: From degradation to subjugation in social relations. Sociology, 23(4), 535-558.

Mansfield, N. (2000). Subjectivity: Theories of the self from Freud to Haraway. Sydney: Allen and Unwin.

Martin, I. (2001). A note of unfashionable dissent: Rediscovering the vocation of adult education in the morass of lifelong learning. Paper presented at the Proceedings of the Standing Committee on University Teaching and Research on the Education of Adults London.

McLaren, M. A. (1997). Foucault and the Subject of Feminism. Social Theory and Practice, 32(1), 109-128.

Newton, T. (1998). Theorising subjectivity in organizations: The failure of Foucauldian studies? Organization Studies, 19(3), 415-449.

Noon, M., \& Blyton, P. (1997). The realities of work. Basingstoke, Hants: Macmillan.

O'Doherty, D., \& Willmot, H. (2001). The question of subjectivity and the labor process. International Studies of Management and Organisation, 30(4), 112-133.

Organisation of Economic Cooperation and Development. (2000). Economics and Finance of Lifelong Learning. Paris: OECD.

Organisation of Economic and Cultural Development (OECD). (1996). Lifelong

Learning for All. Paris: OECD.

Orner, M. (1992). Interrupting the calls for Student Voice in "Liberatory" Education: A Feminist Post structuralist Perspective. In C. Luke \& J. Gore (Eds.), Feminisms and Critical Pedagogy. London: Routledge.

Piaget, J. (1968). Structuralism (C. Maschler, trans. and ed.). London: Routledge \&

Kegan Paul.

Pusey, M. (2003). The Experience of Middle Australia. Cambridge, UK: Cambridge University Press.

Ratner, C. (2000). Agency and culture. Journal for the Theory of Social Behaviour, 30(413434).

Rogers, C. (1969). Freedom to learn. Columbus, Ohio: Charles F Merrill Publishing Co.

Rogoff, B. (1990). Apprenticeship in thinking - cognitive development in social context. New York: Oxford University Press.

Rousseau, J. J. (1968). The Social Contract. London: Penguin.

Rose, N. (1990). Governing the soul: The Shaping of the Private Self. London: Routledge. 
Scribner, S. (1985). Vygostky's use of history. In J. V. Wertsch (Ed.), Culture, communication and cognition: Vygotskian perspectives (pp. 119-145). Cambridge, UK: Cambridge University Press.

Smith, R. (2005) 'Epistemological agency and the new employee'. Australian Journal of Adult Learning, 45 (1)

Somerville, M. (2006). Subjected bodies, or Embodied Subjects:Subjectivity and learning Safety at Work. In S. Billett, T. Fenwick \& M. Somerville (Eds.), Work, subjectivity and learning (pp. 37-52). Dordrecht, The Netherlands: Springer.

Somerville, M., \& Abrahamsson, L. (2003). Trainers and learners Constructing a Community of Practice: Masculine Work Cultures and Learning Saftey in the Mining Industry. Studies in the Education of Adults, 35(1), 19-34.

Taylor, C. (1985). Human Agency and Language: Philosophical Papers 1. Cambridge: Cambridge University Press.

Valsiner, J. (2000). Culture and human development. London: Sage Publications.

Valsiner, J., \& van der Veer, R. (2000). The Social Mind: The construction of an idea. Cambridge, UK: Cambridge University Press.

Weedon, C. (1997). Feminist Practice and Poststructuralist Theory. Massachusetts: Blackwell Publishers.

Wenger, E. (1998). Communities of Practice: Learning, Meaning, and Identity. Cambridge, UK: Cambridge University Press. 